\title{
Enhancement Treatment of Recycled Concrete Aggregate
}

\author{
Kehan Chen ${ }^{1 \dagger}$, Zhaoyue Zhu ${ }^{1 \dagger}$, Tao Xue ${ }^{1 \dagger}$, Heng Zhang ${ }^{1 \dagger}$, Anyang Wang ${ }^{1 \dagger}$, Rui $\mathrm{He}^{1 \dagger}$, \\ Hao Yang ${ }^{1+}$ and Yufei Wang ${ }^{2 * t}$ \\ ${ }^{1}$ School of Architectural Engineering, Nanjing Institute of Technology, Nanjing, China, ${ }^{2}$ School of Design and Built Environment, \\ Curtin University, Perth, WA, Australia
}

Keywords: recycled concrete aggregate, adhered cement mortar, enhancement method, strength, cementitious material

\section{INTRODUCTION}

The quantity of construction and demolition (C\&D) wastes has been growing rapidly in China, accounting for a large proportion of solid wastes. These waste materials lead to serious environmental impacts such as global warming, climate change, and desertification. To address this problem, reusing C\&D wastes is promising since it can reduce waste pollution and simultaneously conserve resources. For instance, the copper tailings and discarded tire rubber have been successfully applied in concrete, illustrating the feasibility of waste recycling in the construction industry (Thomas et al., 2013; Thomas et al., 2015).

Aggregate is an essential component in concrete, occupying 60-70\% of the concrete by

University of Western Australia,

Edited by: Australia

Reviewed by:

Wanhui Feng,

Zhongkai University of Agriculture and

Engineering, China

Genbao Zhang,

Hunan City University, China

*Correspondence:

Yufei Wang

wangyf0113_suz@163.com

${ }^{\dagger}$ These authors have contributed equally to this work and share the first authorship

Specialty section:

This article was submitted to Sustainable Design and Construction, a section of the journal

Frontiers in Built Environment

Received: 10 July 2021 Accepted: 13 July 2021

Published: 22 July 2021

Citation:

Chen $K$, Zhu Z, Xue $T$, Zhang $H$, Wang $A, H e R$, Yang $H$ and Wang $Y$ (2021) Enhancement Treatment of Recycled Concrete Aggregate. Front. Built Environ. 7:739148. doi: 10.3389/fbuil.2021.739148 volume. Nevertheless, the application of natural aggregate (NA) is restricted due to the finite resources and long regeneration period. Recycled concrete aggregate (RCA), as common C\&D waste, has received widespread attention for its usage to replace NA. The RCA has an enormous market potential because of its low recycling cost and universal availability. It can effectively reduce NA usage and concurrently decrease waste land disposal. However, the durability and mechanical properties of concrete containing RCA are usually worse than the traditional NA concrete. Poon et al. (2002) found that the compressive strength of concrete decreased significantly provided the replacement proportion of NA by RCA was over $50 \%$. Compared to the NA, the adhered cement mortar is attached to the RCA, forming the original interface transition zone (ITZ) between the aggregates and binder. This adhered mortar is more porous than NA, resulting in RCA's higher porosity and consequently higher water absorption than NA. The water absorption of RA remarkably increased from $1-5 \%$ to $3-12 \%$ compared to that of NA (Gomez-Soberon, 2002). The adhered mortar content and water-to-cement ratio (W/C) of the original concrete considerably affect the water absorption, density, and strength of RCA. The amount of adhered mortar is related to the RCA crushing process and the particle granularity. The pozzolans and superplasticizers are usually added to RCA concrete to overcome the high water absorption effect and simultaneously improve the concrete fresh and hardened characteristics (Kou et al., 2011).

Generally, the cracking appears in the ITZ prior to other concrete regions mainly due to the higher porosity and more fissures than those in aggregates or hardened cement binder. For RCA concrete, the original ITZs (between original aggregates and adhered mortar) exist apart from the new ITZs (between RCA and cement paste). Therefore, the number of ITZs in RCA concrete is more than that in NA concrete, resulting in reduced mechanical strength. Otsuki et al. (2003) illustrated the significance of the adhered mortar quality to the original ITZ properties through the Vickers microhardness test. In addition, the porosity of the ITZ is essential to the RCA concrete performance, which depends on the W/C value. Specifically, the new ITZs would be more porous and critical than the original ITZs when the W/C ratio in RCA concrete was higher than that in 
original concrete, and vice versa (Ryu, 2002). In conclusion, reducing the RCA water absorption and porosity are crucial to improving the mechanical performance of RCA concrete.

\section{ENHANCEMENT TREATMENT}

To improve the performance of RCA, removing the adhered mortar is verified as a useful approach including pre-soaking in acid and mechanical grinding. However, the pre-soaking method increases the production cost and the grinding method easily forms micro-cracks which damages the RCA structure. Accordingly, enhancing the adhered mortar performance receives extensive attention comprising the following practical solutions. The polymer emulsions (e.g. polyvinyl alcohol and silane-base polymers) are usually implemented to coat the RCA surface, reducing the RCA water absorption. Besides, RCA can be treated in pozzolanic solutions prior to its application as concrete aggregates. The pozzolans such as fly ash and silica fume can fill the RCA voids, participating in the pozzolanic reaction to form calcium silicate hydrates (C-S-H) gels. This treatment can reduce the porosity of RCA and simultaneously improve the strength of ITZs. The sodium silicate solution is also feasible to treat RCA for the reason of its reaction with calcium hydroxide to generate $\mathrm{C}-\mathrm{S}-\mathrm{H}$ gels. In addition, the adhered mortar mainly consists of calcium hydroxide and C-S-H gels. Therefore, carbon dioxide can react with these composites, which has been verified to reduce the water absorption and porosity of RCA.

\section{DISCUSSION}

The polymer emulsion method can effectively improve the RCA quality, together with the durability and workability of the recycled concrete. However, the mechanical performance enhancement is limited which is probably attributed to the silane hydrolysis which blocks the cement hydration. Meanwhile, the membrane in the RCA surface is water repellent, which diminishes the bond strength between the cement paste and the aggregates.

Regarding pozzolanic solution treatment, the pozzolanic materials attached to the RCA surface react with calcium

\section{REFERENCES}

Chen, J. J., Thomas, J. J., and Jennings, H. M. (2006). Decalcification Shrinkage of Cement Paste. Cement concrete Res. 36 (5), 801-809. doi:10.1016/j.cemconres.2005.11.003

Gomez-Soberon, J. (2002). Porosity of Recycled concrete with Substitution of Recycled concrete Aggregate: an Experimental Study. Cem. Concr. Res. 32 (8), 1301e1311. doi:10.1016/s0008-8846(02)00795-0

Kou, S.-C., Poon, C.-S., and Etxeberria, M. (2011). Influence of Recycled Aggregates on Long Term Mechanical Properties and Pore Size Distribution of concrete. Cement and Concrete Composites 33 (2), 286-291. doi:10.1016/ j.cemconcomp.2010.10.003 hydroxide to generate C-S-H gels, effectively strengthening the ITZs' performance and increasing the RCA density. Therefore, the mechanical properties and durability of RCA concrete are improved. Nevertheless, the efficacy depends on the granularity and reactivity of the pozzolanic materials, and the calcium hydroxide content in the adhered mortar. The nano-silica is efficient owing to its high reactivity and fine granularity, whereas the application cost is expansive (Singh et al., 2013).

The concentration of sodium silicate solution and the RCA soaking time considerably influence the treated RCA performance. The optimal concentration and time were $5 \%$ and $1 \mathrm{~h}$, respectively (Chen et al., 2006). However, excessive sodium silicate and soaking time will lead to the reduced mechanical properties of the RCA and RCA concrete. Furthermore, the usage of sodium silicate can increase the risk of excessive expansion caused by the alkali-silica reaction.

Carbonation of calcium hydroxide and C-S-H gels can generate solid calcium carbonate to fill the pores and voids of the adhered mortar. This leads to the increase of the solid volume and consequently reduced porosity. Zhang et al. (2015b) declared that carbonation significantly increased the density and decreased the water absorption of the RCA. This method is also eco-friendly due to the consumption of carbon dioxide. Thereby, carbonation treatment is feasible and optimal for RCA improvement among four pretreatment approaches.

\section{AUTHOR CONTRIBUTIONS}

$\mathrm{KC}$ : conceptualization and methodology. $\mathrm{ZZ}$ and $\mathrm{HZ}$ : methodology and conceptualization. TX: writing. YW: conceptualization, methodology, and revising, AW: reviewing and editing. RH and HY: supervision. All authors contributed to the article and approved the submitted version.

\section{FUNDING}

This research was supported by the Jiangsu 2021 Students' innovation and entrepreneurship training program (ID: 202111276019Z, 202111276020Z).

Otsuki, N., Miyazato, S. I., and Yodsudjai, W. (2003). Inflfluence of Recycled Aggregate on Interfacial Transition Zone, Strength, Chloride Penetration and Carbonation of concrete. J. Mater. Civ. Eng. 15 (5), 443e451. doi:10.1061/(asce) 0899-1561(2003)15:5(443)

Poon, C. S., Kou, S. C., and Lam, L. (2002). Use of Recycled Aggregates in Molded concrete Bricks and Blocks. Constr. Build. Mater. 16 (5), 281e289. doi:10.1016/ s0950-0618(02)00019-3

Ryu, J. S. (2002). Improvement on Strength and Impermeability of Recycled concrete Made from Crushed concrete Coarse Aggregate[J]. J. Mater. Sci. Lett. 21 (20), 1565-1567. doi:10.1023/a:1020349011716

Singh, L. P., Karade, S. R., Bhattacharyya, S. K., Yousuf, M. M., and Ahalawat, S. (2013). Beneficial Role of Nanosilica in Cement Based Materials - A Review. 
Construction Building Mater. 47, 1069-1077. doi:10.1016/ j.conbuildmat.2013.05.052

Thomas, B. S., Damare, A., and Gupta, R. C. (2013). Strength and Durability Characteristics of Copper Tailing concrete. Constr. Build. Mater. 48, 894e900. doi:10.1016/j.conbuildmat.2013.07.075

Thomas, B. S. G., and Chandra, R. (2015). Long Term Behaviour of Cement concrete Containing Discarded Tire Rubber. J. Clean. Prod. 102, $78 \mathrm{e} 87$. doi:10.1016/j.jclepro.2015.04.072

Zhang, J., Shi, C., Li, Y., Pan, X., Poon, C., and Xie, Z. (2015b). Performance Enhancement of Recycled concrete Aggregates through Carbonation. J. Mater. Civ. Eng. 7, 04015029.
Conflict of Interest: The authors declare that the research was conducted in the absence of any commercial or financial relationships that could be construed as a potential conflict of interest.

Copyright (c) 2021 Chen, Zhu, Xue, Zhang, Wang, He, Yang and Wang. This is an open-access article distributed under the terms of the Creative Commons Attribution License (CC BY). The use, distribution or reproduction in other forums is permitted, provided the original author(s) and the copyright owner(s) are credited and that the original publication in this journal is cited, in accordance with accepted academic practice. No use, distribution or reproduction is permitted which does not comply with these terms. 